\title{
Steady-State Kinetics and Mutational Studies of Recombinant Human Thiamin Pyrophosphokinase
}

\author{
Mari ONOZUKA ${ }^{1}$ and Kazuto NosAKA ${ }^{2, *}$ \\ ${ }^{1}$ Department of Biochemistry, Kyoto Prefectural University of Medicine, Kamigyo-ku, Kyoto 602-8566, Japan \\ ${ }^{2}$ Department of Chemistry, Kyoto Prefectural University of Medicine, Kita-ku, Kyoto 603-8334, Japan
}

(Received December 27, 2002)

\begin{abstract}
Summary Thiamin pyrophosphokinase catalyzes the pyrophosphorylation of thiamin to thiamin pyrophosphate in the presence of ATP and $\mathrm{Mg}^{2+}$. The kinetic properties of human thiamin pyrophosphokinase (hTPK1) were investigated using purified histidine-tagged recombinant protein. The plots of the initial velocity against MgATP concentrations gave a sigmoidal character when $\mathrm{Mg}^{2+}$ /ATP was maintained at 1 . However, the addition of an excess amount of $\mathrm{Mg}^{2+}$ resulted in the restoration of activity at lower concentrations of MgATP. A steady-state kinetics study led us to conclude that the kinase reaction obeys a ping-pong mechanism. Site-directed mutagenesis was also performed on hTPK1 to examine the contributions of eight strictly conserved residues in thiamin pyrophosphokinase on the kinetic properties. Mutations D71N, D73N, and D100N reduced $k_{\text {cat }}$ markedly, indicating that these aspartic acids play a crucial role in carrying out the catalytic process of hTPK1. A selective decrease in the $k_{\text {cat }} / \mathrm{Km}^{\text {thiamin }}$ value was observed in the D133N mutant, whereas the $k_{\text {cat }} / \mathrm{Km}^{\mathrm{ATP}}$ values of T99A and R131G were significantly decreased. Interestingly, the replacement of Gln-96 with Glu caused an increase in the $k_{\text {cat }} / \mathrm{Km}^{\text {thiamin }}$ value (3.53-fold of the wild-type). It was therefore suggested that the residues Gln-96, Thr-99, Arg-131, and Asp-133 are conserved as functionally significant components for substrate recognition in thiamin pyrophosphokinase.
\end{abstract}

Key Words thiamin pyrophosphokinase, thiamin, thiamin pyrophosphate, steady-state kinetics, site-directed mutagenesis

Thiamin occurs in cells as free thiamin and as its phosphate esters, thiamin monophosphate, thiamin pyrophosphate (TDP), and thiamin triphosphate $(1,2)$. TDP is a cofactor for many enzymes indispensable for glucose and energy metabolism, including pyruvate dehydrogenase, 2-oxoglutarate dehydrogenase, transketolase, and others $(1,2)$. The primary structures and conformations of many of these TDP-dependent enzymes have been well studied, and the mechanism and configuration of TDP as a transient intermediate carrier of the aldehyde group in the enzymes have been characterized (3). In addition to its coenzymatic function, TDP is a precursor for thiamin triphosphate, which may have non-cofactor effects on neurologic cells (4-6). Since many types of neural symptoms emerge in diseases caused by thiamin deficiency or congenital impairments of thiamin metabolism (1), thiamin phosphate esters are of critical significance to cell viability and function in vertebrates.

Thiamin pyrophosphokinase (EC 2.7.6.2) catalyzes the pyrophosphorylation of thiamin to TDP in the presence of ATP and $\mathrm{Mg}^{2+}$. This enzyme is absolutely

* To whom correspondence should be addressed.

E-mail: knosaka@basic.kpu-m.ac.jp

Abbreviations: hTPK1, human thiamin pyrophosphokinase; TDP, thiamin pyrophosphate. required for TDP synthesis and has been purified from several eucaryotic sources and procaryote, Paracoccus denitrificans (7-11), and the nucleotide sequences have been determined for mammalians, yeasts, and the prokaryote (12-15). Thiamin pyrophosphokinase exists mainly in the dimer form of identical subunits whose relative molecular masses range from 23,000 to 36,000. While enzyme kinetics studies of thiamin pyrophosphokinase have been reported by some investigators, two types of the reaction mechanism have so far been proposed. Voskoboyev and Ostrovsky (9) indicated, using purified yeast and rat liver enzymes, that the reaction obeys an ordered sequential mechanism, and the same mechanism has been postulated for the parsley leaf enzyme (10). On the other hand, Thomé-beau et al. (16) demonstrated that the yeast enzyme functions via a ping-pong mechanism, and Peterson et al. (17) suggested a partial ping-pong mechanism for the pig brain enzyme. In addition, since thiamin pyrophosphokinase has no amino acid sequence similarity to other proteins including kinases, ATP-binding proteins, thiamin-binding proteins, and TDP-dependent enzymes, residues involved in substrate recognition or catalysis have not been suggested.

We recently isolated a human thiamin pyrophosphokinase (hTPK1) cDNA and assigned the chromosomal localization of the gene (15). The hTPK1 polypeptide 
contains 243 amino acid residues, has a calculated relative molecular mass of 27,265 , and its mRNA is widely expressed in various human tissues at a very low level. In this study, the steady-state kinetics of hTPK1 were characterized using the purified histidine-tagged fusion protein, and the data provided proof of a ping-pong mechanism rather than a sequential mechanism. Furthermore, the eight amino acid residues strictly conserved in hTPK1 were altered individually by sitedirected mutagenesis. Their kinetic parameters were determined and compared with those of the recombinant wild-type hTPK1.

\section{MATERIALS AND METHODS}

Materials. The bacterial expression vector pRSEThTPK1 coding for wild-type hTPK1 with a six histidinetag at the N-terminus, which has been described previously (15), was used to purify the protein and for sitedirected mutagenesis. Thiamin hydrochloride and thiamin pyrophosphate chloride were purchased from Nacalai Tesque (Kyoto, Japan). All other chemicals were of analytical grade.

Expression and purification of wild-type and mutant hTPK1. The Escherichia coli strain BL21(DE3)pLysS was transformed with the expression vector coding for a histidine-tagged wild-type or mutant hTPK1. Induction of the recombinant protein and preparation of the cell extracts were done as described previously (15). The histidine-tagged proteins were purified from the crude bacterial extracts using magnetic nickel-agarose beads (MagExtractor ${ }^{\circledR}$-His-tag-, Toyobo, Osaka, Japan) according to the manufacturer's instructions. In the case of further purification, we carried out size exclusion chromatography using a TSKgel ${ }^{\circledR}$ G3000SW $(7.5 \times 600$ $\mathrm{mm}$ ) column (Toyo Soda, Tokyo, Japan) with $0.25 \mathrm{~m}$ Tris-acetate buffer, $\mathrm{pH}$ 7.0. The protein concentration was determined using a protein assay kit (Bio-Rad, Hercules, CA) with BSA as the standard.
Enzyme assay and kinetic data analysis. The thiamin pyrophosphokinase activity was assessed by determining the amount of enzyme product TDP using HPLC after conversion to thiochrome by alkaline oxidation with cyanogen bromide as previously described (12). In the standard assay, $1.5 \mathrm{~mL}$ of a mixture containing $0.02 \mathrm{M}$ Tris- $\mathrm{HCl}, \mathrm{pH} 7.5,0.1 \mathrm{~mm}$ thiamin, $2 \mathrm{~mm}$ ATP, 5 $\mathrm{mM} \mathrm{MgCl}_{2}$, and purified enzyme (about $1 \mu \mathrm{g}$ ) was incubated at $37^{\circ} \mathrm{C}$ for 5 to $30 \mathrm{~min}$. The reaction was stopped with $0.3 \mathrm{~mL}$ of $30 \%$ trichloroacetic acid, and TDP in the fluid was extracted with ethyl ether (12). In the steadystate kinetics study, initial velocity data were obtained under conditions in which the concentration of one substrate was varied at several constant concentrations of the second substrate. In all cases the data were linear with respect to time and enzyme concentration in the range employed, and the data reported here were all carried out in duplicate. Kinetic parameters were analyzed graphically by constructing double-reciprocal plots of initial velocities and substrate concentrations. Line fitting was performed with KaleidaGraph (Synergy Software, Reading, PA, USA).

Site-directed mutagenesis. Site-directed mutagenesis was performed by the inverse PCR method described by Stemmer and Morris (18). The key step in this method is the incorporation of identical class $2 \mathrm{~s}$ restriction sites in both primers that are used to amplify the entire plasmid. A class 2 s restriction enzyme has a recognition site that is located $5^{\prime}$ of the cut site (e.g., BsmBI: CGTCTCN'NNNN). The primers used to generate point mutations are listed in Table 1. PCR was performed with the primer pairs for 30 cycles using Advan taq ${ }^{\mathrm{TM}}$ polymerase (BD Biosciences Clontech, Palo Alto, CA) and the plasmid pRSET-hTPK1 as the template. Each cycle consisted of denaturation at $95^{\circ} \mathrm{C}$ for $30 \mathrm{~s}$, annealing at $48^{\circ} \mathrm{C}$ for $30 \mathrm{~s}$, and extension at $72^{\circ} \mathrm{C}$ for $180 \mathrm{~s}$. After finishing PCR, the ends of the full-length linearized plasmids were digested with BsmBI leaving plas-

Table 1. Oligonucleotides used for mutagenesis.

\begin{tabular}{|c|c|c|c|c|}
\hline Mutant & Amino acid changed & Mutagenic primer & Nucleotide position & Sequence \\
\hline \multirow[t]{2}{*}{$\mathrm{D} 71 \mathrm{~N}$} & \multirow{2}{*}{$\mathrm{Asp}^{71} \rightarrow$ Asn } & forward & $209-229$ & 5'-CGTCTCGAAACTTTGATTCTATTAGGC-3' \\
\hline & & reverse & $195-214$ & 5'-CGTCTCAGTTTCCATTGATGAATTCA-3' \\
\hline \multirow[t]{2}{*}{ D73N } & \multirow[t]{2}{*}{$\mathrm{Asp}^{73} \rightarrow \mathrm{Asn}$} & forward & $215-234$ & 5'-CGTCTCTTA-ĀTTCTATTAGGCCTGAA-3' \\
\hline & & reverse & $201-220$ & 5'-CGTCTCAATTAAAGTCTCCATTGATG-3' \\
\hline \multirow{2}{*}{ S74A } & \multirow{2}{*}{$\mathrm{Ser}^{74} \rightarrow$ Ala } & forward & $218-235$ & 5'-CGTCTCATĞ̄TATTAGGCCTGAAG-3' \\
\hline & & reverse & $204-223$ & 5'-CGTCTCTAḠCATCAAAGTCTCCATTG-3' \\
\hline \multirow[t]{2}{*}{ Q96E } & \multirow[t]{2}{*}{$\mathrm{Gln}^{96} \rightarrow \mathrm{Glu}$} & forward & $284-301$ & 5'-CGTCTCATG-̄AAGACCACACTGACT-3' \\
\hline & & reverse & $272-289$ & 5'-CGTCTCCTTCATCAGGAGTTGAAA-3' \\
\hline \multirow[t]{2}{*}{ T99A } & \multirow[t]{2}{*}{ Thr $^{99} \rightarrow$ Ala } & forward & $293-312$ & 5'-CGTCTCACGCTGACTTTACTAAGTGC-3' \\
\hline & & reverse & $281-298$ & 5'-CGTCTCCAḠCGTGGTCTTGATCAG-3' \\
\hline \multirow[t]{2}{*}{ D100N } & \multirow[t]{2}{*}{ Asp $^{100} \rightarrow$ Asn } & forward & $296-313$ & 5'-CGTCTCCTA- \\
\hline & & reverse & $284-301$ & 5'-CGTCTCAGTTAGTGTGGTCTTGAT-3' \\
\hline \multirow[t]{2}{*}{ R131G } & \multirow[t]{2}{*}{$\operatorname{Arg}^{131} \rightarrow$ Gly } & forward & $389-411$ & 5'-CGTCTCGGGGTTTTGACCAGATTATGGCA-3' \\
\hline & & reverse & $378-394$ & 5'-CGTCTCAACECCCCAGCAAGGCCT-3' \\
\hline \multirow{2}{*}{ D133N } & \multirow[t]{2}{*}{$\mathrm{Asp}^{133} \rightarrow \mathrm{Asn}$} & forward & $395-414$ & 5'-CGTCTCTTA-ACCAGATTATGGCATCT-3' \\
\hline & & reverse & $383-400$ & 5'-CGTCTCGGTTAAAACGCCCAGCAA-3' \\
\hline
\end{tabular}

Nucleotides underlined are the sequences mutated and nucleotides in italics are the restriction site of BsmBI. Nucleotide position is numbered according to the hTPK1 open reading frame (EMBL accession number AB028138). 
mids with compatible overhangs on both ends. The digested DNAs were purified on an agarose gel, and ligated with T4 DNA ligase (Promega, Madison, WI). Because the NNNN overhang was the only part that became part of the plasmid in this ligation step, the native sequence could be made. Sequencing analysis using an ABI prism 377 DNA sequencer (Applied Biosystems, Foster City, CA) was carried out to confirm the presence of only the desired mutation and no other unintentional change.

\section{RESULTS AND DISCUSSION}

Purification of recombinant histidine-tagged hTPK1

A histidine-tagged hTPK1 was generated and purified from E. coli BL21(DE3)pLysS using magnetic nickelagarose beads. As shown in Fig. 1, the recombinant protein was greatly overproduced in the bacterial cells when induced with isopropyl- $\beta$-D-thiogalactopyranoside (lane 3), and only one step on the beads was required for almost complete purification (lane 4). About $400 \mu \mathrm{g}$ of the purified protein was obtained from $20 \mathrm{~mL}$ of culture. The migration of the polypeptide corresponding to $\mathrm{Mr}$ of 30,000 in SDS/PAGE gels was almost consistent with the calculated value. The relative molecular mass of the protein determined by size exclusion chromatography was estimated to be 61,000 (data not shown), showing a homodimeric structure. A trace amount of contaminators could be detected spectrophotometrically. However, the specific enzyme activity was not increased after the protein was further fractionated. We therefore carried out experiments in this study with the protein purified using only the magnetic beads. The specific activity of this fraction was $60.2 \mathrm{nmol}$ TDP formed $\mathrm{mg}^{-1} \mathrm{~min}^{-1}$, which was 1.4 times higher than the activity of the native thiamin pyrophosphokinase purified from human red blood cells (7).

Divalent cation and nucleoside triphosphate requirement

A nucleoside triphosphate and a divalent cation are requisites for pyrophosphate transfer in the thiamin pyrophosphokinase reaction. The requirements of the nucleoside triphosphates and divalent cations for hTPK1 activity under standard conditions are shown in Table 2. An absolute requirement of $\mathrm{Mg}^{2+}$ for the activity was replaced to some extent by $\mathrm{Co}^{2+}$ among a number of the divalent cations tested. When $\mathrm{Mg}^{2+}$ was replaced by $\mathrm{Zn}^{2+}, \mathrm{Mn}^{2+}, \mathrm{Ca}^{2+}$, or $\mathrm{Cu}^{2+}$, however, the activity was much lower. On the other hand, UTP appeared to be a highly effective pyrophosphate donor, as the performance was twice that of ATP. CTP was $62 \%$ as effective as ATP, whereas the enzyme scarcely used GTP as a cosubstrate for its activity. The result for UTP was distinct from the previous result using the native human enzyme (7), and the explanation for the difference remains obscure. Thus, hTPK1 has broad specificity for divalent cations and nucleoside triphosphates. However, ATP and $\mathrm{Mg}^{2+}$ are assumed to be uti-

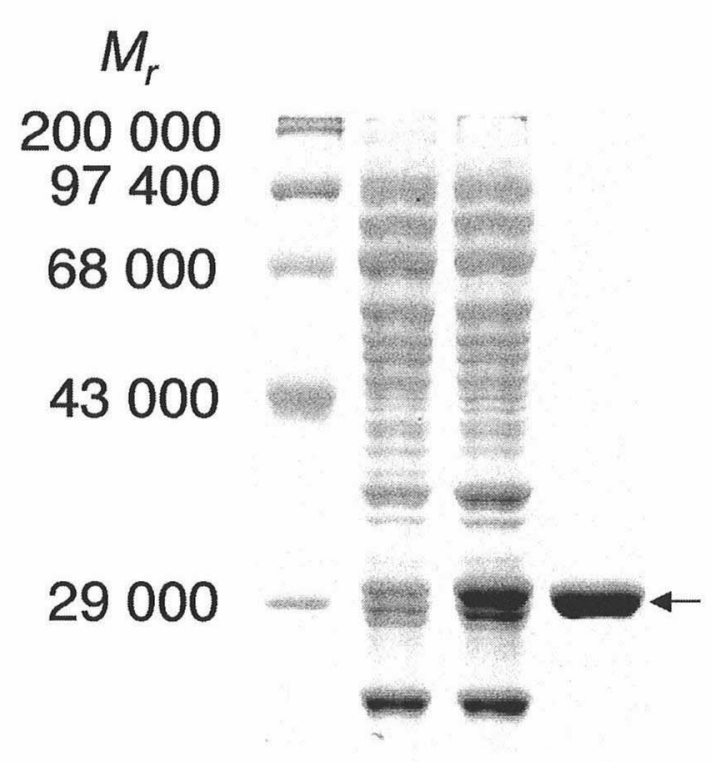

18400

\section{0}

\section{$\begin{array}{llll}1 & 2 & 3 & 4\end{array}$}

Fig. 1. Expression and purification of histidine-tagged hTPK1 protein. Crude extracts (5 $\mu \mathrm{g}$ of protein) of isopropyl- $\beta$-D-thiogalactopyranoside-induced bacterial cells (lane 3 ) and uninduced cells (lane 2), and purified fraction (4 $\mu \mathrm{g}$ of protein, lane 4 ) were analyzed using $12.5 \%$ SDS/PAGE followed by Coomassie blue staining. The position of the histidine-tagged hTPK1 protein is indicated by an arrow. Lane 1 shows the molecular standard proteins (Life Technologies).

Table 2. Requirements of divalent cation and nucleotide for hTPK1 activity.

\begin{tabular}{cccc}
\hline Divalent cation & Specific activity $(\mathrm{nmol} \mathrm{mg}$ & Nucleotide & Specific activity $\left(\mathrm{nmol} \mathrm{mg}^{-1} \mathrm{~min}^{-1}\right)$ \\
\hline $\mathrm{MgCl}_{2}$ & $60.2(100)$ & ATP & $60.2(100)$ \\
$\mathrm{CoCl}_{2}$ & $54.6(90.6)$ & UTP & $125(207)$ \\
$\mathrm{ZnCl}_{2}$ & $16.3(27.0)$ & CTP & $37.3(31.4)$ \\
$\mathrm{MnCl}_{2}$ & $10.2(16.8)$ & GTP & $11.0(18.3)$ \\
$\mathrm{CaCl}_{2}$ & $4.4(7.3)$ & ADP & NA \\
$\mathrm{CuCl}_{2}$ & $1.3(2.2)$ & & \\
\hline
\end{tabular}

The activity was assayed under standard conditions as described in Materials and Methods, except for the kind of divalent cation or nucleotide. The percent activity is given in parentheses. NA indicates that no activity was detected. 


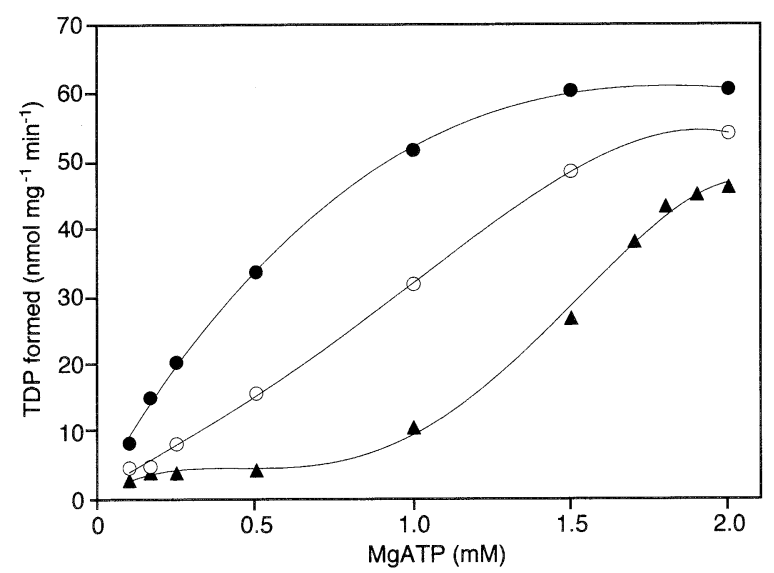

Fig. 2. Relationship between MgATP concentrations and initial velocity. The velocity was determined under standard conditions as described in Materials and Methods, except for the concentrations of $\mathrm{Mg}^{2+}$ and ATP: equimolar mixture of $\mathrm{Mg}^{2+}$ and ATP (O), $5 \mathrm{mM}$ $\mathrm{Mg}^{2+}$ and various concentrations of ATP $(\bullet)$ and various concentrations of $\mathrm{Mg}^{2+}$ and $2 \mathrm{mM} \operatorname{ATP}(\mathbf{\Lambda})$.

A

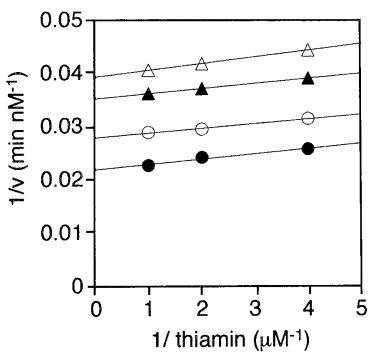

C

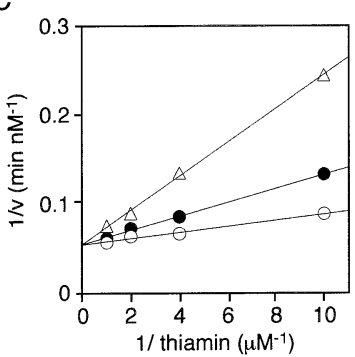

B

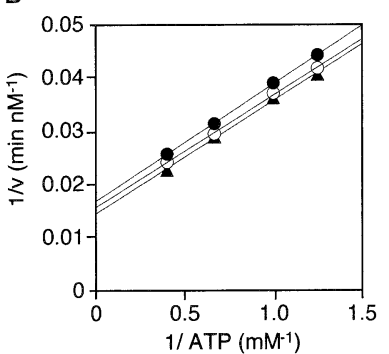

D

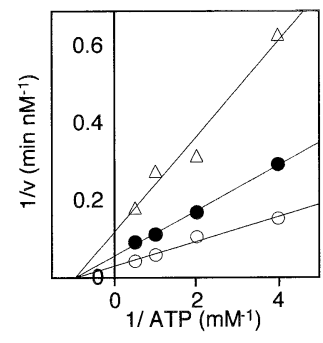

Fig. 3. Initial velocity and product inhibition patterns of hTPK1 reaction. The reactions were initiated with $1.4 \mu \mathrm{g}$ of purified enzyme. (A) Plots of $1 / v$ versus $1 /$ [thiamin] at various levels of ATP and at a constant concentration of $\mathrm{Mg}^{2+}(5 \mathrm{mM})$. ATP concentration was fixed at $0.8 \mathrm{~mm}(\triangle), 1.0 \mathrm{~mm}(\mathbf{\Delta}), 1.5 \mathrm{~mm}(\mathrm{O})$ and 2.0 $\mathrm{mM}(\bullet)$. (B) Plots of $1 / v$ versus $1 /$ [ATP] at various levels of thiamin and at a constant concentration of $\mathrm{Mg}^{2+}$ ( $5 \mathrm{mM}$ ). Thiamin concentration was fixed at $0.25 \mu \mathrm{M}$ $(\bullet), 0.5 \mu \mathrm{M}(\mathrm{O})$ and $1.0 \mu \mathrm{M}(\mathbf{\Delta})$. (C) Double-reciprocal plots of the initial velocity versus the thiamin concentration at various concentrations of AMP. ATP concentration was fixed at $0.5 \mathrm{mM}$. AMP concentrations were $5 \mathrm{~mm}(\triangle), 2 \mathrm{mM}(\bullet)$ and $0 \mathrm{~mm}(\mathrm{O})$. (D) Double-reciprocal plots of the initial velocity versus the ATP concentration at various concentrations of AMP. Thiamin concentration was fixed at $0.25 \mu \mathrm{M}$. AMP concentrations were $100 \mathrm{~mm}(\triangle), 50 \mathrm{~mm}(\bullet)$ and $0 \mathrm{~mm}(0)$.

lized for the hTPK1 reaction under physiological conditions.

The variation in the initial velocity with varying ATP and $\mathrm{Mg}^{2+}$ concentrations was examined. When the ratio of $\mathrm{Mg}^{2+} /$ ATP was maintained at 1 , the curve illustrated in Fig. 2 (open circle) shows a typical sigmoidal characteristic. It is noted that there was still a significant, 10-35\%, amount of free ATP within the concentration range in this experiment although the MgATP complex form prevails in an equimolar mixture since the apparent stability constant for the complex is around $5 \times 10^{4} \mathrm{M}^{-1}$ under mild alkaline conditions (19). The curve corrected by calculating the amount of MgATP complex form was also sigmoidal (data not shown). When a fixed but excessive amount of $\mathrm{Mg}^{2+}$ was added, the activities at lower concentrations of MgATP were restored and hyperbolic curves were obtained (Fig. 2, closed circle). On the other hand, the substrate saturation curve became more sigmoidal with the addition of a fixed but excessive amount of ATP (Fig. 2 , closed triangle). It seems reasonable to assume that free ATP competes with MgATP at the active sites, although the possibility of ATP as an allosteric inhibitor cannot be ruled out. However, it is unlikely that ATP would inhibit the biosynthesis of TDP in vivo since the total intracellular concentration of $\mathrm{Mg}^{2+}$ is around 17 mм and usually much higher than that of ATP.

Steady-state kinetic properties

In order to probe the catalytic mechanism, steadystate kinetic studies were undertaken in the presence of excess $\mathrm{Mg}^{2+}$ ( $5 \mathrm{~mm}$ ). The double-reciprocal plots of initial velocity as a function either of the thiamin concentration (in the range of $0.25-1.0 \mu \mathrm{M}$ ) at several ATP concentrations $(0.8-2.0 \mathrm{~mm})$ or of the ATP concentration at several levels of thiamin concentration yielded apparently parallel lines with a constant slope (Fig. 3A and $\mathrm{B})$. We also adopted another fixed concentration of excess $\mathrm{Mg}^{2+}(2 \mathrm{~mm})$ with several ATP concentrations $(0.4-1.0 \mathrm{~mm})$, and the plots were never convergent (data not shown). Next, a product inhibition experiment was performed. The inhibition patterns with AMP were determined at varied concentrations of one substrate and at constant level of the other substrate unsaturated. In Fig. 3C, a series of lines intersect at the vertical axis, indicating that AMP competitively inhibited the activity with respect to thiamin. On the other hand, the double-reciprocal plots in Fig. 3D depict that the type was noncompetitive with respect to ATP. Such patterns are indicative of a ping-pong mechanism (Fig. 4)

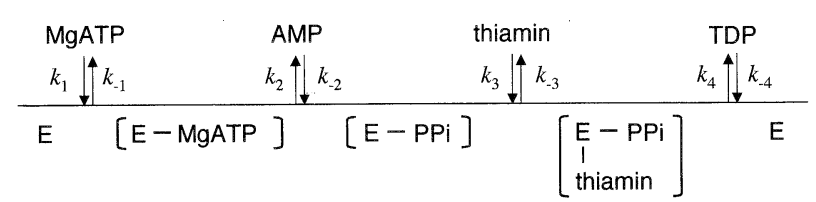

Fig. 4. The individual steps of the hTPK1 reaction in a ping-pong mechanism (Cleland plot). Abbreviation "E" represents hTPK1, and $k$ is a rate constant in the individual step. 
rather than a sequential mechanism as defined by Cleland (20). The data were fit to Eq. (1) using the least squares method.

$$
\begin{array}{r}
v=k_{\text {cat }}[\mathrm{E}][\mathrm{ATP}][\text { thiamin }] /\left(\mathrm{Km}^{\mathrm{ATP}}[\text { thiamin }]\right. \\
\left.+\mathrm{Km}^{\text {thiamin }}[\mathrm{ATP}]+[\mathrm{ATP}][\text { thiamin }]\right)
\end{array}
$$

Where [E], [ATP], and [thiamin] are concentrations of enzyme, ATP, and thiamin; $\mathrm{Km}^{\text {ATP }}$ and $\mathrm{Km}^{\text {thiamin }}$ are Michaelis constants for ATP and thiamin; and $k_{\text {cat }}$ is a turnover number based on the relative molecular mass for the histidine-tagged hTPK1. According to Eq. (1), the kinetic constants of the histidine-tagged hTPK1 were obtained (Table 3$)$. The $\mathrm{Km}^{\text {ATP }}$ value $(1.2 \mathrm{mM}$ ) was smaller than, but in the same range of that of the purified thiamin pyrophosphokinase from human red blood cells $(2.5 \mathrm{mM})$, whereas the $\mathrm{Km}^{\text {thiamin }}$ value $(0.21 \mu \mathrm{M})$ was larger $(0.10 \mu \mathrm{M})(7)$. It was supposed that the affinities of hTPK1 for both substrates are essentially unaffected by the fused six histidine-tag. The conclusion from this result is, however, incompatible with those of previous articles that postulated an ordered sequential mechanism $(9,10)$. This marked discrepancy may be attributable to the complexity of the behavior of this enzyme in relation to $\mathrm{Mg}^{2+}$ and ATP (17) or the difference in the enzyme source, although the precise reason is unknown.

Using a schematic method by King and Altman (21), Eqs. (2)-(4) describe the relationship between the kinetic parameters and microscopic rate constants given in Fig. 4. In the process of derivation, the concentrations of the AMP and TDP products are negligible at early times in the reaction.

$$
\begin{aligned}
& v /[\mathrm{E}]= k_{1} k_{2} k_{3} k_{4}[\mathrm{ATP}][\text { thiamin }] / \\
&\left(k_{1} k_{3}\left(k_{2}+k_{4}\right)[\mathrm{ATP}][\text { thiamin }]\right. \\
&+k_{1} k_{2}\left(k_{-3}+k_{4}\right)[\mathrm{ATP}] \\
&\left.+k_{3} k_{4}\left(\mathrm{k}_{-1}+k_{2}\right)[\text { thiamin }]\right) \\
& k_{\text {cat }} / \mathrm{Km}^{\mathrm{ATP}}=k_{1} k_{2}\left(k_{-1}+k_{2}\right) \\
& k_{\text {cat }} / \mathrm{Km}^{\text {thiamin }}=k_{3} k_{4} /\left(\mathrm{k}-3+k_{4}\right)
\end{aligned}
$$

Equations (3) and (4) indicate that, in the case of a ping-pong mechanism, $k_{\text {cat }} / \mathrm{Km}^{\text {ATP }}$ and $k_{\text {cat }} / \mathrm{Km}^{\text {thiamin }}$ simply represent an apparent second-order rate constant of the respective reaction under low substrate concentrations (22). As shown in Table 3, the $k_{\text {cat }} / \mathrm{Km}^{\text {ATP }}$ value of the wild-type hTPK1 seems very low $\left(59 \mathrm{~s}^{-1} \mathrm{M}^{-1}\right)$, whereas the $k_{\text {cat }} / \mathrm{Km}^{\text {thiamin }}$ value is above $10^{5} \mathrm{~s}^{-1} \mathrm{M}^{-1}$. It is noted here that $k_{1}$ is the rate constant for the association of hTPK1 and MgATP. Since the association rate constants are in the range of $10^{6}$ to $10^{8} \mathrm{~s}^{-1} \mathrm{M}^{-1}(22)$, the dissociation constant $k_{-1}$ is predicted, from Eq. (3), to be much greater than $k_{2}$. The finding that MgATP is easy

Table 3. Kinetic parameters for wild-type and mutant hTPK1 proteins.

\begin{tabular}{llcccc}
\hline \multicolumn{1}{c}{ Enzyme } & $k_{\text {cat }}\left(\mathrm{s}^{-1}\right)$ & $\mathrm{Km}^{\mathrm{ATP}}(\mathrm{mM})$ & $\mathrm{Km}^{\text {thiamin }}(\mu \mathrm{M})$ & $k_{\text {cat }} / \mathrm{Km}^{\mathrm{ATP}}\left(\mathrm{s}^{-1} \mathrm{M}^{-1}\right)$ & $k_{\text {cat }} / \mathrm{Km}^{\text {thiamin }}\left(\mathrm{s}^{-1} \mathrm{M}^{-1}\right)$ \\
\hline Wild-type & 0.069 & 1.2 & 0.21 & $5.9 \times 10$ & $3.3 \times 10^{5}$ \\
D71N & 0.0005 & $\mathrm{ND}$ & $\mathrm{ND}$ & - & - \\
D73N & 0.0003 & $\mathrm{ND}$ & $\mathrm{ND}$ & - & $4.1 \times 10^{5}$ \\
S74A & 0.094 & 2.4 & 0.23 & $4.0 \times 10$ & $1.2 \times 10^{6}$ \\
Q96E & 0.045 & 1.0 & 0.039 & 7.4 & - \\
T99A & 0.026 & 3.5 & 0.16 & $1.6 \times 10^{5}$ \\
D100N & 0.0002 & $\mathrm{ND}$ & $\mathrm{ND}$ & - & $3.7 \times 10^{5}$ \\
R131G & 0.028 & 2.0 & 0.076 & $5.2 \times 10$ & $4.1 \times 10^{4}$ \\
D133N & 0.034 & 0.65 & 0.82 & \\
\hline
\end{tabular}

Kinetic parameters represent best-fit values by fitting Eq. (1) to rate measurements at various substrate concentrations. Each value is the mean from two experiments. ND indicates that Km values could not be defined for these mutants due to their very low activity.

H.sapiens
M.musculus
D.melanogaster
C.elegans
A.thaliana
S.pombe
S.cerevisiae
P.denitrificans

Fig. 5. Partial amino acid sequence of hTPK1 aligned with other thiamin pyrophosphokinases. Amino acid sequences of thiamin pyrophosphokinases from Homo sapiens (hTPK1, EMBL accession number AB028138), Mus musculus (AB027568), Drosophila melanogaster (AE003692), Caenorhabditis elegans (Z11115), Arabidopsis thaliana (T01602), Schizosaccharomyces pombe (X84417), Saccharomyces cerevisiae (D14417) and Paracoccus denitrificans (E10547) were aligned using the ClustalW program (http://www2.ebi.ac.uk/clustalw/). Numbers on the upper side of the sequence indicate the amino acid position of hTPK1. The apparent highly similar regions are indicated by thick lines. Identical residues are indicated by an asterisk and similar residues are indicated by a dot. The amino acids shown in bold type in the hTPK1 sequence represent the residues that were altered by site-directed mutagenesis in this study. 
to dissociate from the enzyme complex may be correlated with the high degree of solvent accessibility of the likely MgATP-binding site (23).

Mutational studies

We compared the amino acid sequences of thiamin pyrophosphokinases including the homologs that emerged from the Genome project of any species. Although those enzymes share only $15-30 \%$ sequence identity with each other, except between mammalian enzymes, three highly similar regions were found to be located in the middle of the sequences (Fig. 5). We began a site-directed mutagenesis approach by targeting the strictly conserved residues in these regions to examine their contributions to the catalytic function of thiamin pyrophosphokinase. Especially, we focused on the residues, shown in bold type in Fig. 5, that might play roles in catalytic reaction. All of the mutant proteins comigrated with the wild-type protein, both in SDS/PAGE gels and size exclusion chromatography (data not shown), suggesting that none of the amino acid residues introduced with mutation are essential for the dimer formation of the hTPK1 polypeptide.

The steady-state kinetic parameters of the purified mutant enzymes were determined and compared to the wild-type hTPK1 (Table 3). When aspartic acids 71, 73, and 100 were replaced by an asparagine (D71N, D73N, or D100N), the enzyme activity fell to almost the lower limit of detection and the $K_{m}$ values could not be defined. This finding suggests that these acidic residues may participate directly in the catalytic reactions, and therefore, they are critical for hTPK1 activity. As for the other mutants (S74A, Q96E, T99A, R131G, and D133N), although the $k_{\text {cat }}$ values ranged from 0.38 - to 1.4-fold of the wild-type enzyme, several pieces of information were obtained from the variation in more important $k_{\text {cat }} / \mathrm{Km}$ values. The $k_{\text {cat }} / \mathrm{Km}^{\text {thiamin }}$ value of D133N was 0.12 -fold the wild-type enzyme owing to a significant increase in the $\mathrm{Km}^{\text {thiamin }}$ value, whereas $k_{\text {cat }}$ / $\mathrm{Km}^{\text {ATP }}$ was similar to the wild-type enzyme, indicating that Asp-133 is involved in the interaction with thiamin. Interestingly, the replacement of Gln-96 with Glu caused a significant decrease in the $\mathrm{Km}^{\text {thiamin }}$ value and a resultant increase in the $k_{\text {cat }} / \mathrm{Km}^{\text {thiamin }}$ value (3.6-fold of the wild-type enzyme). On the other hand, the $k_{\text {cat }} /$ $\mathrm{Km}^{\text {ATP }}$ values of T99A and R131G were 0.13- and 0.24-fold the wild-type enzyme, respectively, indicating that the interaction with MgATP is influenced by the replacement of Thr-99 and Arg-131 to a nonpolar amino acid, and both residues may be involved in the interaction with MgATP.

Recently, Timm and co-workers $(23,24)$ determined the crystal structures of mouse and yeast thiamin pyrophosphokinases complexed with thiamin. They demonstrated that thiamin pyrophosphokinase polypeptide folds as an $\mathrm{N}$-terminal $\alpha / \beta$-domain and a C-terminal $\beta$ sandwich domain containing a central ten-stranded $\beta$ sheet. The subunits associate as a dimer, and the dimer contains two thiamin-binding sites at the subunit interface, which forms a cleft between the $\alpha / \beta$-domain of one subunit and the $\beta$-sandwich of the other subunit.
According to their definitive evidence, Asp-71, Asp100, and Arg-131 are in close proximity to the hydroxyethyl group of thiamin, and in particular, Asp-100 forms a water-mediated contact with the group. They also speculated that the aspartate residues $(71,73$, and 100) and Arg-131 appear to be involved in interaction with MgATP. On the other hand, the main-chain carbonyl oxygen atom of Gln-96 makes contact with the positively charged thiazolium ring of thiamin. These arrangements are compatible with the results from the mutagenesis analysis in this study. The increase in the affinity for thiamin in the Q96E mutant might be brought about by the electrostatic interaction between the negative charge on the side-chain of the glutamic acid and the thiazolium ring. We propose that the functional group of conserved Asp-100 with Asp-71 and Asp-73 plays a crucial role, such as pyrophosphoryl transfer, in carrying out the catalytic process of hTPK1, although further molecular and chemical investigations are necessary to clarify the mechanism in the interaction of these residues with pyrophosphate and thiamin.

\section{Acknowledgments}

The authors are grateful to Professor Hoyoku Nishino for reading of the manuscript. This work was supported in part by Grant-in-aid for Scientific Research (C) 13671196 from the Japan Society for the Promotion of Science.

\section{REFERENCES}

1) Friedrich W. 1988. Vitamins. Walter de Gruyter, Berlin.

2) Leder IG. 1975. Thiamine, biosynthesis and function. In: Metabolism of Sulfur Compounds, Metabolic Pathway (Greenberg DM, ed), 3rd ed. Vol 7, p 57-85. Academic Press, New York.

3) Schellenberger A. 1998. Sixty years of thiamin diphosphate biochemistry. Biochim Biophys Acta 1385: 177186.

4) Cooper JR, Pincus JH. 1979. The role of thiamine in nervous tissue. Neurochem Res 4: 223-239.

5) Matsuda T, Cooper JR. 1981. Thiamine as an integral component of brain synaptosomal membranes. Proc Natl Acad Sci USA 78: 5886-5889.

6) Nghiêm H-O, Bettendorff L, Changeux J-P. 2000. Specific phosphorylation of Torpedo $43 \mathrm{~K}$ rapsyn by endogenous kinase(s) with thiamine triphosphate as the phosphate donor. FASEB J 14: 543-554.

7) Egi Y, Koyama S, Shioda T, Yamada K, Kawasaki T. 1992. Identification, purification and reconstitution of thiamin metabolizing enzymes in human red blood cells. Biochim Biophys Acta 1160: 171-178.

8) Wakabayashi Y. 1978. Purification of thiamine pyrophosphokinase from pig brain. Vitamins 52: 223-228 (in Japanese).

9) Voskoboyev AI, Ostrovsky YM. 1982. Thiamin pyrophosphokinase: structure, properties, and role in thiamin metabolism. Ann NY Acad Sci 378: 161-176.

10) Mitsuda H, Takai Y, Iwami K, Yasumoto K. 1975. Mechanism and regulation of thiamine pyrophosphokinase from parsley leaf. J Nutr Sci Vitaminol 21: 189-198.

11) Sanemori H, Kawasaki T. 1980. Purification and prop- 
erties of thiamine pyrophosphokinase in Paracoccus denitrificans. J Biochem 88: 223-230.

12) Nosaka K, Kaneko Y, Nishimura H, Iwashima A. 1993. Isolation and characterization of a thiamin pyrophosphokinase gene, THI80, from Saccharomyces cerevisiae. J Biol Chem 268: 17440-17447.

13) Fankhauser H, Zurlinden A, Schweingruber A-M, Edenharter E, Schweingruber ME. 1995. Schizosaccharomyces pombe thiamine pyrophosphokinase is encoded by gene $\operatorname{tnr} 3$ and is a regulator of thiamine metabolism, phosphate metabolism, mating, and growth. J Biol Chem 270: 28457-28462.

14) Nosaka K, Onozuka M, Nishino H, Nishimura H, Kawasaki Y, Ueyama H. 1999. Molecular cloning and expression of a mouse thiamin pyrophosphokinase cDNA. J Biol Chem 274: 34129-34133.

15) Nosaka K, Onozuka M, Kakazu N, Hibi S, Nishimura H, Nishino H, Abe T. 2001. Isolation and characterization of a human thiamine pyrophosphokinase cDNA. Biochim Biophys Acta 1517: 293-297.

16) Thomé-beau F, Lan LT, Olomucki A, Thoai NV. 1969. ATP: thiamine pyrophosphotransferase. Purification and a study of the reaction mechanism. Biochim Biophys Acta 185: 111-121.
17) Peterson JW, Gubler CJ, Kuby SA. 1975. Partial purification and properties of thiamine pyrophosphokinase from pig brain. Biochim Biophys Acta 397: 377-394.

18) Stemmer WPC, Morris SK. 1992. Enzymatic inverse PCR: a restriction site independent, single-fragment method for high-efficiency, site-directed mutagenesis. BioTechniques 13: 215-220.

19) O'Sullivan WJ, Smithers GW. 1979. Stability constants for biologically important metal-ligand complexes. Methods Enzymol 63: 294-336.

20) Cleland WW. 1963. The kinetics of enzyme-catalyzed reactions with two or more substrates of products. Biochim Biophys Acta 67: 104-137.

21) King EL, Altman C. 1956. A schematic method of deriving the rate laws for enzyme-catalyzed reactions. $J \mathrm{Am}$ Chem Soc 60: 1375-1378.

22) Fersht A. 1985. Enzyme Structure and Mechanism, 2nd ed. W. H. Freeman and Co., New York.

23) Timm DE, Liu J, Baker L-J, Harris RA. 2001. Crystal structure of thiamin pyrophosphokinase. J Mol Biol 310: 195-204.

24) Baker L-J, Dorocke JA, Harris RA, Timm DE. 2001. The crystal structure of yeast thiamin pyrophosphokinase. Structure 9: 539-546. 